\title{
A Preliminary Investigation of Preferred Affiliative Interactions within and between Select Bonded Pairs of Horses: A First Look at Equine "Love Languages"
}

Kieson $\mathrm{E}^{1 *}$ and Sams J ${ }^{2}$

${ }^{1}$ MiMer Centre, Sweden

${ }^{2}$ School of Equine Management and Science, Royal Agricultural University, UK

*Corresponding author: Emily Kieson, MiMer Centre, Björnahusvägen 6, 26193 Saxtorp, Sweden, Tel: +15125175227; Email: emily@mimercentre.org

\section{Research Article}

Volume 4 Issue 4

Received Date: July 28, 2021

Published Date: August 19, 2021

DOI: $10.23880 /$ izab-16000318

\section{Abstract}

Recent research in equine pro-social behavior has shifted from agonistic and aggressive behaviors to a greater emphasis on affiliative interactions. With increased prioritization of physiological and psychological welfare in horses, studies have begun to focus not only on understanding stress behaviors, but also how to improve recognition of positive emotional affects in equine behaviors and the contexts in which they take place. Previous research in affiliative interactions focused on proximity and allogrooming as indicators of affiliative bonds between horses and can be used as a foundation for studying additional affiliative interactions that are exclusive between bonded pairs. This study is a preliminary investigation of behaviors exhibited between twelve bonded pairs of quarter horse mares of reproductive age living in large, socially stable herds. The goal of this study is to create a preliminary list of behaviors that occur exclusively between horse friends that indicate behavioral demonstrations of affection. Researchers used proximity indicators to identify bonded pairs and focused on coding behaviors that horses voluntarily expressed with their chosen friends and not with other mares. Researchers used video data to log and count behaviors within and between pairs to look for differences in individual preferences for affiliative interactions (whether presenting or receiving) and to determine any differences between how each pair exhibits affiliative interactions. Behaviors observed included initiation of allogrooming, touching body with nose, deliberately moving head over or under the head and neck of their partner, placing head over the back of partner, and moving to closer proximity. All twelve pairs demonstrated behaviors of initiating closer proximity indicating affiliative preference. Each pair also exhibited at least two other affiliative behaviors with only one pair partaking in allogrooming behavior. Individuals within pairs also differed in their preferred affiliative interactions, suggesting that individual horses have unique preferences for expressing and receiving affiliative behaviors which may differ from their partner's preferences. This study can serve as a preliminary foundation for examining how horses choose to demonstrate affection and can inform interpretations of psychological welfare in horses and provide new insights into horse-human interactions.

Keywords: Equine Affiliative Behavior; Horse Friendships; Love Languages; Equine Preferred Conspecifics 


\section{International Journal of Zoology and Animal Biology}

\section{Introduction}

Research in animal friendships is a relatively new field with many previous studies looking at the interactions of "preferred conspecifics" rather than labeling these bonded individuals as friends. Studies over the last decade, however, have begun to use the word "friend" as a means of distinguishing behaviors that one animal exhibits to a preferred partner versus others in their social realm [13]. This emphasis on nonhuman friendship recognizes that these preferences and behaviors towards specific individuals indicates a relationship out of affection, desire, and psychological need rather than a behavior strictly for physical survival [3]. Researchers have therefore begun to recognize that animals have close affiliations that can be categorized as friendships [3]. The unique interactions between pairs, therefore, suggests a new approach and potential methodologies for understanding friendship between nonhuman pairs as a means of understanding new ways that species relate to each other within and between species [4]. Much of the recent research in animal friendship has focused on primates and behavioral indicators between pairs that demonstrate specialized ways of expressing preference and affection such as those done in chimpanzees $[1,2,5,6]$ and baboons which has served to inform other areas of animal friendships [7,8].

In order to distinguish animal friendships from other pro-social behaviors, researchers have looked at variations in voluntary behaviors (rather than trained responses) in an effort to study friendships between animals, including social networks and intraspecies signals. In general, social networks are often established for protection from predators, division of labor, and to lower stress levels through integration of linked affiliates and development of communication [9]. The development of social signals therefore helps to establish a predictable pattern of behavior and reliance on which each individual can depend for their physical and psychological safety [9]. Many of these signals are used to convey preference for proximity and companionship through the use of signaling social attraction or repulsion [9]. Many studies in horse social interactions often focus on these repulsion signals, emphasizing agonistic and dominance behaviors over potential affiliative responses. Such studies often focus exclusively on the agonistic behaviors between domestic (rather than feral) horses $[10,11]$ emphasizing the pinning of ears, kicking, baring teeth, and larger behaviors where horses might bite, kick, or chase each other. Studies in horses have also focused on the concept of social hierarchy with emphasis on looking at agonistic behaviors as a means of assessing "dominant" horses within a herd [12-14]. Stress has also been a focus of management studies to assess the behavioral response of horses to human handling and housing strategies [15-17] with some studies focusing on the affects of longterm stress on the development of stereotypic behaviors $[18,19]$. These stress, dominance, and agonistic signals have been studied extensively in horses, yet there are fewer research studies into the signals horses use with their favorite conspecifics to indicate the facilitation of social connection.

The limited research into bonded pairs between horses has often focused on allogrooming and chosen proximity, with each serving as behavioral indicators of close affiliations of horses. Often allogrooming and approach (without agonistic or aggressive behaviors) are the only behavioral indicators of affiliative interactions $[20,21]$ with play behavior also being an indicator for stallion preferences for play partners but not necessarily an indicator for strong social bonds between stallions [10]. Allogrooming has also served an indicator of socially bonded pairs. Observational studies of domestic and feral horses have shown that allogrooming only occurs between bonded pairs of conspecifics and more frequently during and after stressful experiences [22-27]. Allogrooming has therefore been used as a means by which to determine preferred conspecifics and equine affiliative partners $[10,21]$. One study suggests that horses will even intervene when their favorite conspecific would allogroom with another horse, but not if they played with another horse, VanDierendonck et al. [26], suggests that allogrooming may be a stronger indicator of friendship than play.

Proximity also plays a role in determining preference for partners in a wide range of animals and the importance of proximity in horse friendship has received support from studies in equine ethology. Research shows that free-living horses often group in dyads (sometimes triads) and that these pairings congregate into slightly larger groups that will further come together to form the entire herd [28]. Bonds between individuals are also not random as horses have been shown to choose specific partners, with proximity preference indicating stronger bonds between individuals of the same sex and reproductive state. Proximity is also used to determine stallion preference for affiliates and playmates [10] when provided with free choice of partners. Kinship can affect affiliative relationships but is not necessarily the defining factor. Behavioral similarities (in dominance or agonistic behaviors that are linked to suggested dominance ranking) are also linked to social affiliative preferences exhibited through those who choose closer proximity to one another [29,30]. Agonistic behaviors are also seen between members of the same sex or herd and have been linked with proximity preference rather than dominance or resource sharing Heitor, et al. [31] suggests that proximity and spacesharing is of greater importance than resources and provides a stronger indicator of affiliative preference. 
The aim of this study was to examine behaviors exhibited exclusively between horse pairs that already demonstrated preference for proximity and who may have demonstrated mutual grooming behaviors. The goal of this study is to create a preliminary list of behaviors that occur exclusively between horse friends that indicate behavioral demonstrations of affection with or without the context of stress. The purpose is to establish baseline ethograms and begin developing methods by which owners and equine scientists can evaluate the positive welfare of horses based on their unique interaction preferences with bonded partners.

\section{Materials and Methods}

\section{Horse Population}

Videos were recorded at a breeding facility in central Oklahoma that exclusively houses quarter horses. A total of 200 horses were recorded during the dates of May 1, 7, and 24 of 2019 between the hours of 09:30 and 13:00. One herd (Herd 1) consisted of 85 horses and the other (Herd 2) consisted of 115 horses. All horses were quarter horse mares of breeding age (ages 6-20) and all had been at the facility for at least two years living in stable social groups for the duration of their stay. Horses live permanently in large outdoor pastures in these two separate herds and are able to freely exhibit preferences for other conspecifics through free choice of proximity.

Video recordings were taken using 14 GoPro Hero cameras (Hero model number CHDHA-301, GoPro Inc, San Mateo, CA, USA, purchased used on Ebay) attached to fences around the equine property in central Oklahoma. The property encompasses approximately 160 acres split into multiple pastures with three primary pastures enclosing approximately 40 acres each. Eleven cameras were positioned around the pastures containing horses (only two pastures were in use during the recording window, therefore five cameras were positioned around one pasture while six were positioned at regular intervals along the fence in the other pasture) while three cameras were positioned around the smaller pens (two pens of approximately 2 acres each) closer to the palpation/ insemination barn. Each day around 10:00am, each herd is brought to these smaller pens in order to separate out the mares that need palpating to determine ovulation. Mares that need palpating are separated out from the herd while the remaining horses return to the pasture. Once each mare is palpated, they return to the pasture with their known herd mates. The total duration of handling by humans is approximately ten minutes every second or third day. For the remainder of the time, horses live in pastures with free access to hay/grass and water.
Videos were collected for both the pastures and small collection pens with a total of at least 105 minutes of video recorded with each camera on the dates in May.

\section{Coding Behaviors}

Two researchers observed behavioral patterns on a total of twelve separate pairs of horses that exhibited preference for proximity (allowance for or desire for close proximity of under approximately $3 \mathrm{~m}$ with lack of agonistic or aggressive behaviors by either conspecific) under either pasture or small pen conditions. Such visual approximations and techniques used to determine proximity (and preference for proximity) has been shown to be valid. While GPS tracking systems can be used to establish more specific proximity between partners, observational approaches are also found to be robust when considering the general proximity between two individuals and the relation to social networks of the group [32].

In order to determine potential behaviors, both researchers first observed at least one hour of video of all of the pairs to look for behaviors that were specific to bonded pairs that exhibited proximity. Since allogrooming has been identified as only occurring between bonded equine conspecifics, this behavior was not counted since the purpose of this study is to identify other behaviors that are exclusive to horse friends. The researchers mutually agreed upon the following list of behaviors that were displayed in exclusive friendships:

"Initiating close proximity" - when one horse deliberately moves to be close to the other horse. Both horses may show preference for close proximity, but this is a behavior that indicates one horse is making the movements to position him/her closer to the other.

"Head over back" - where horses put their head over the back or rump of their horse friend and leave it there for a duration of at least 3 seconds without any indication of initiating allogrooming (Figure 1).

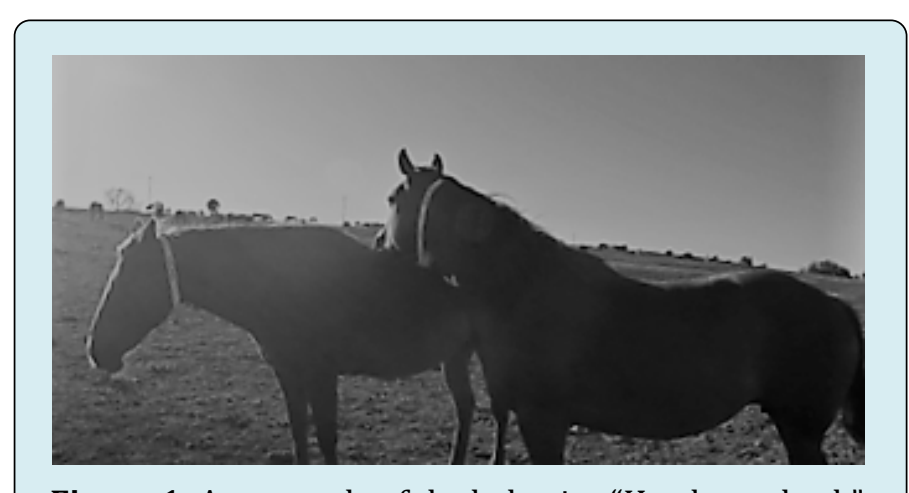

Figure 1: An example of the behavior "Head over back". 
"Nose touch to other's body" - when the horse touches its nose to its friend's body without initiating nuzzle movement to indicate allogrooming. This nose touch lasts for at least $1 \mathrm{~s}$ (Figure 2).

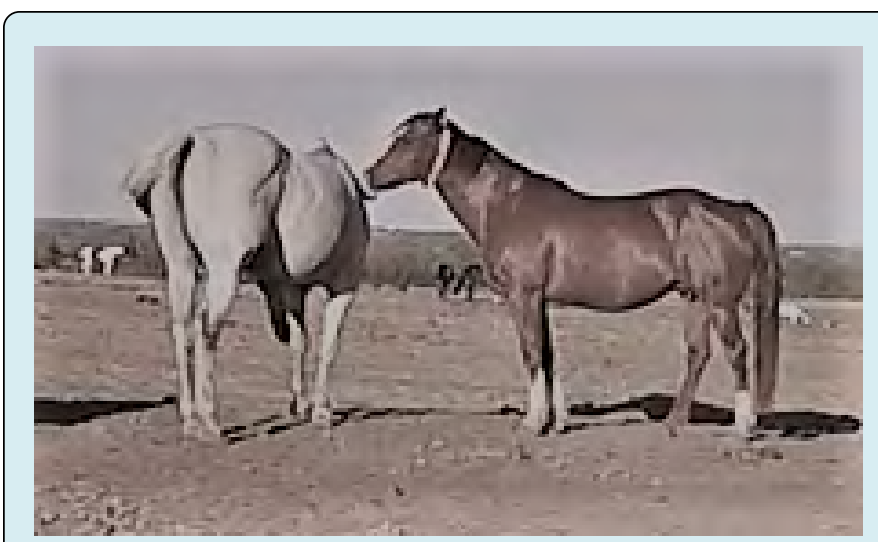

Figure 2: An example of the behavior "Nose touch other's body".

"Head/Neck over other's head/neck" - when the horse deliberately moves its head/neck over the other's head/ neck. The horse may leave it there or it may be a movement. For this action the horse deliberately moves OVER the other horse (Figure 3).

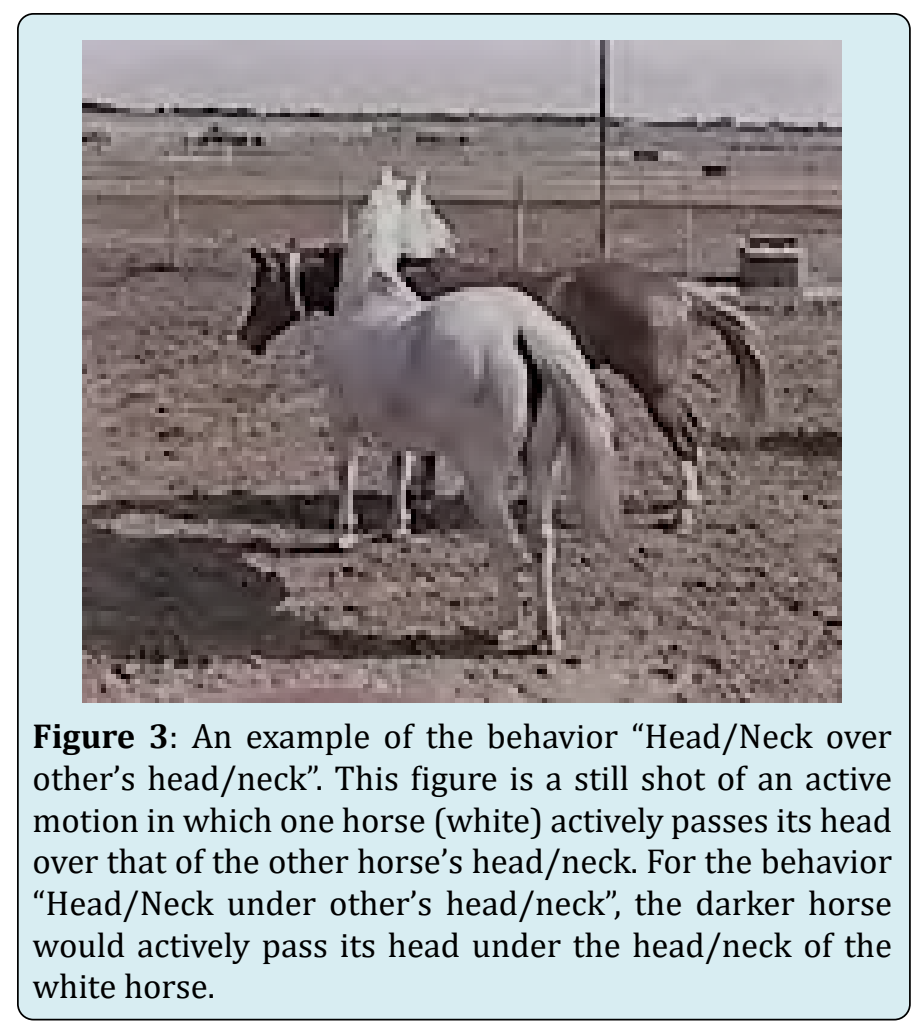

"Head/Neck under other's head/neck" - when the horse deliberately moves its head/neck under the other's head/ neck. The horse may leave it there or it may be a movement. For this action the horse deliberately moves UNDER the other horse. The position of the horses looks the same as the above, but the difference is that one horse chooses to move under the other horse whereas the previous behavior ("over") is initiated by the horse that moves over the other (Figure 3).

"Initiating Allogrooming" - when one horse positions itself opposite and alongside the other and begins nuzzling the other's neck/crest/withers to initiate all grooming. This behavior is restricted to the asking and initiation of allogrooming. The reciprocation of all grooming may not occur so the behavior of initiating allogrooming may also be brief (Figure 4).

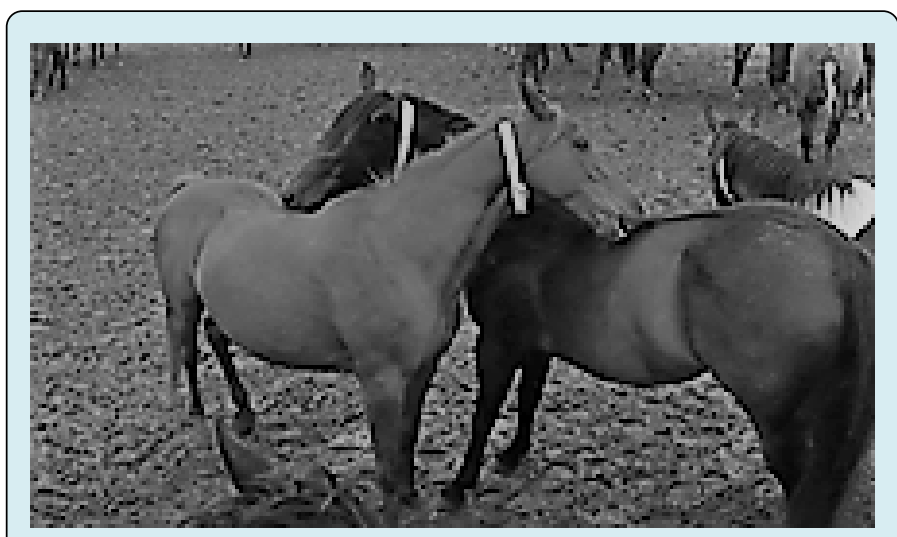

Figure 4: An example of allogrooming behavior. This photograph is of allogrooming when the grooming was mutual and reciprocated.

Researcher 1 chose recognizable pairs from videos from Herd 1 while researcher 2 chose recognizable pairs from videos from Herd 2. In order to follow each pair, researchers chose horses with distinctive markings so as to be able to follow them when they chose to group with others. Each researcher was required to follow and record behaviors from each pair for at least 30 minutes with the purpose of recording behaviors that were expressed exclusively between bonded individuals. These behaviors were defined as being behaviors that were expressed by either horse with the bonded conspecific (or conspecifics if it was a triad) but were not expressed with any other horse and were not identified as aggressive, agonistic, or guarding (using mild agonistic behaviors to stop bonded horse from approaching or to position the body between the bonded conspecific and the potential threat or novelty [33].

\section{Results}

Researcher 1 recorded data on six pairs of horses in Herd 1 with 45 minutes of observation recorded for each 
pair. Researcher 2 recorded data on six pairs of horses in Herd 2 with an average observation time of 29 min (one pair was only visible for 21 minutes). Observations included both pasture and small pen observations.

Researchers observed that each pair demonstrated unique affiliative behavior patterns that differed from other pairs so that not all behaviors were expressed by all pairs. When behaviors were observed, they were often observed no more than 4 times within the 30 minutes of observation. Exceptions occurred for individual pairs rather than types of interactions with some pairs expressing certain behaviors in much greater frequency than others (Table 1).

\begin{tabular}{|c|c|c|c|c|c|c|c|}
\hline $\begin{array}{l}\text { Horse } \\
\text { Pair }\end{array}$ & Horses & $\begin{array}{l}\text { Initiating } \\
\text { Close } \\
\text { Proximity } \\
\end{array}$ & $\begin{array}{c}\text { Head } \\
\text { over } \\
\text { Back } \\
\end{array}$ & $\begin{array}{l}\text { Nose } \\
\text { Touch }\end{array}$ & $\begin{array}{c}\text { Head/Neck Over } \\
\text { Other's Head/ } \\
\text { Neck }\end{array}$ & $\begin{array}{c}\text { Head/Neck } \\
\text { Under Other's } \\
\text { Head/Neck } \\
\end{array}$ & $\begin{array}{c}\text { Initiating } \\
\text { Allogrooming }\end{array}$ \\
\hline \multirow{2}{*}{$\begin{array}{c}\text { Herd } 1 \\
\text { Pair } 1 \\
\end{array}$} & Horse 1 & 1 & 2 & 3 & 2 & 8 & 0 \\
\hline & Horse 2 & 4 & 2 & 6 & 4 & 0 & 0 \\
\hline \multirow{2}{*}{$\begin{array}{l}\text { Herd } 1 \\
\text { Pair } 2 \\
\end{array}$} & Horse 1 & 2 & 0 & 3 & 0 & 0 & 0 \\
\hline & Horse 2 & 3 & 0 & 3 & 0 & 0 & 0 \\
\hline \multirow{2}{*}{$\begin{array}{c}\text { Herd } 1 \\
\text { Pair } 3 \\
\end{array}$} & Horse 1 & 0 & 0 & 2 & 0 & 0 & 0 \\
\hline & Horse 2 & 3 & 1 & 1 & 0 & 2 & 0 \\
\hline \multirow{2}{*}{$\begin{array}{c}\text { Herd } 1 \\
\text { Pair } 4 \\
\end{array}$} & Horse 1 & 2 & 1 & 2 & 0 & 0 & 0 \\
\hline & Horse 2 & 1 & 3 & 1 & 0 & 1 & 0 \\
\hline \multirow{2}{*}{$\begin{array}{c}\text { Herd } 1 \\
\text { Pair } 5 \\
\end{array}$} & Horse 1 & 1 & 0 & 0 & 0 & 0 & 0 \\
\hline & Horse 2 & 1 & 0 & 0 & 0 & 0 & 0 \\
\hline \multirow{2}{*}{$\begin{array}{c}\text { Herd } 1 \\
\text { Pair } 6 \\
\end{array}$} & Horse 1 & 2 & 0 & 0 & 0 & 0 & 0 \\
\hline & Horse 2 & 1 & 0 & 0 & 0 & 0 & 0 \\
\hline \multirow{2}{*}{$\begin{array}{c}\text { Herd } 2 \\
\text { Pair } 1 \\
\end{array}$} & Horse 1 & 5 & 0 & 11 & 1 & 0 & 0 \\
\hline & Horse 2 & 2 & 0 & 0 & 0 & 0 & 0 \\
\hline \multirow{2}{*}{$\begin{array}{c}\text { Herd } 2 \\
\text { Pair } 2 \\
\end{array}$} & Horse 1 & 1 & 0 & 0 & 0 & 0 & 0 \\
\hline & Horse 2 & 6 & 0 & 4 & 0 & 0 & 0 \\
\hline \multirow{2}{*}{$\begin{array}{c}\text { Herd } 2 \\
\text { Pair } 3 \\
\end{array}$} & Horse 1 & 3 & 1 & 4 & 0 & 1 & 0 \\
\hline & Horse 2 & 3 & 2 & 2 & 0 & 0 & 0 \\
\hline \multirow{2}{*}{$\begin{array}{c}\text { Herd } 2 \\
\text { Pair } 4 \\
\end{array}$} & Horse 1 & 2 & 0 & 1 & 0 & 3 & 1 \\
\hline & Horse 2 & 2 & 2 & 2 & 0 & 0 & 0 \\
\hline \multirow{2}{*}{$\begin{array}{c}\text { Herd } 2 \\
\text { Pair } 5 \\
\end{array}$} & Horse 1 & 3 & 2 & 1 & 0 & 0 & 0 \\
\hline & Horse 2 & 2 & 0 & 0 & 0 & 0 & 0 \\
\hline \multirow{2}{*}{$\begin{array}{c}\text { Herd } 2 \\
\text { Pair } 6 \\
\end{array}$} & Horse 1 & 3 & 1 & 0 & 0 & 0 & 0 \\
\hline & Horse 2 & 4 & 1 & 0 & 0 & 0 & 0 \\
\hline
\end{tabular}

Table 1: Number of times each individual horse in each pair of horses was observed demonstrating specific behaviors for the duration of the observation.

\section{Proximity}

At least one horse in each of the twelve pairs demonstrated behaviors of initiating proximity with their preferred partner. In nine of the twelve pairs one horse initiated proximity more frequently than the other. Within these nine pairs, partners within five of the pairs only differed in the frequency of initiating proximity by one. The difference in frequency of initiating closer proximity in the other four pairs was three. One pair included only one horse who willingly initiated closer proximity.

\section{Head Over Back}

Eight of the twelve pairs exhibited behaviors where one horse chose to put its head over the back or rump of the affiliated partner. Out of these eight pairs, three pairs included interactions where only one horse exhibited this behavior. 


\section{Nose Touch to Other's Body}

Nine of the twelve pairs exhibited this behavior and four of the nine pairs that demonstrated this behavior involved only one horse that showed this type of interaction. In one case, for one pair in Herd 2, one individual of the pair exhibited this behavior eleven times during the observed time (21 minutes of observation) with no similar behavior from her affiliated partner.

\section{Head/Neck Over Other's Head/Neck}

Two of the twelve pairs exhibited this behavior with frequencies of each individual ranging from 1 to 4 times for the 30 minutes of observation. One pair included two individuals that each expressed this behavior while one pair included only one horse that demonstrated this behavior.

\section{Head/Neck Under Other's Head/Neck}

Five of the twelve pairs exhibited this behavior and within all five pairs only one horse in each pair demonstrated this behavior. All but one horse demonstrated this behavior between one and three times with one horse exhibiting this behavior 8 times during observation ( 45 minutes of observation for this specific pair).

\section{Initiating Allogrooming}

Only one of the twelve pairs involved the initiation of allogrooming behavior. The initiation of allogrooming (mutual grooming) only occurred once during the observed period with one horse initiating the interaction.

At least five pairs of horses were observed under both pasture and pen conditions. All pairs of horses who were observed in the smaller pens (used for separating horses for palpation) demonstrated higher frequency of behaviors compared to pasture conditions. All pairs exhibited at least two additional affiliative behaviors in addition to proximity with only one pair demonstrating allogrooming behaviors.

\section{Discussion}

The findings of this preliminary study suggest that horses have multiple ways of expressing affection for their equine friends but it may be limited to a number of specific behavioral patterns that are equine-specific with each individual preferring one or more ways to express emotional bonding. Mutual grooming (allogrooming) has been used to determine preferences for equine [25] but it does not always occur between bonded individuals and it is therefore important to recognize other behavioral indicators of affection and mutual bonds.
In the results of this study allogrooming was observed only once during the observation time, further suggesting that there are other behavioral indicators of affiliation that may be preferred for pairs of bonded horses. These behaviors include when horses choose to hold their head over the back or rump of the other, touch their nose/muzzle to the other, and pass their head/neck over or under the other. With the exception of one horse, all horses observed initiated closer proximity with their preferred partner at some point during the observed time. This behavior is supported by existing research suggesting that horses who choose close proximity with another conspecific can be seen to prefer the company of that horse over that of others, indicating stronger social bonds and friendship [28,29,31]. Since the duration of observation was limited to 45 minutes, it is possible that the horse may have exhibited this behavior outside of the observation window. The initiation of closer proximity within each pair, however, indicates preference for affiliation which can be used to support the categorization for other voluntary, prolonged (without agonistic responses), and reciprocated behaviors as affiliative.

For the behavior "Head over Back" (Figure 1), eight of the twelve pairs exhibited this behavior and three of these pairs included interactions where only one horse exhibited this behavior. This suggests that while it can be categorized as an affiliative interaction (since it only takes place between bonded partners who demonstrate a desire for close proximity), it is not expressed by all horses, nor is it an affiliative behavior that is always shared within bonded pairs.

For the behavior "Nose Touch to Other's Body" (Figure 2), nine of the twelve pairs exhibited this behavior and four of these pairs involved only one horse that showed this type of interaction. The preference for this behavior in only nine of the pairs suggests that, much like the "Head over Back", this is one type of affiliative interaction, but the preference for it is dependent upon both pairs and individuals within pairs. This is especially true for the one horse (Herd 2, Pair 1, Horse 1; Table 1) who demonstrated this behavior 11 times while her partner did not exhibit the behavior at all. As with the other behaviors within pairs, this pattern suggests that individual horses have unique preferences for demonstrating affiliative behaviors while their partner may not share the same affiliative strategy (but may be willing to receive the interaction despite no desire to perform it).

Regarding the behaviors for "Head/Neck over Other's Head/Neck" and "Head/Neck Under Other's Head/Neck", two of the pairs exhibited the behavior for "Head/Neck Over Other's Head/Neck" while five of the pairs exhibited the behavior "Head/Neck Under Other's Head/Neck". Only one pair expressed both the behavior of passing the head over 
as well as under the other horse and this was the only pair of horses in which both horses expressed the behavior (in this case it was Head/Neck over Other's Head/Neck). All other pairs that expressed either of these behaviors included only one horse in the pair that was observed showing the behavior. This one pair also exhibited the behaviors in greater frequency, suggesting not just a strong desire for this behavior but also the need to express it at a higher rate. While there was no indication that this behavioral pattern would attract or maintain a friendship, the similarity of strength and type affiliative expression is something that needs to be considered when examining equine partnerships.

The frequency of the behavior of "Initiating Allogrooming" was of great interest since allogrooming and mutual grooming are often seen as indicators of affiliative partners. Within the twelve pairs, however, only one pair was observed allogrooming and it only occurred once during the duration of observation. The lack of allogrooming within the group of observed horses further suggests that allogrooming is only one indicator of social bonding between pairs.

The expression of each behavior by one, but not both horses also suggests that the voluntary expression of each behavior within this affiliative partnership may be a function of how each horse desires to express affiliation with that specific partner and potentially others. While allogrooming has been shown to have physiological effects on heart rate variability in horses [34] which has been linked to coping strategies in pairs during and after stress [27], other behaviors, like nose touching, head over back, and the passing of the head and neck over or under the other's head or neck may simply be expressions of affection between two individual horses, with each horse having a preference for how to express his or her affection or affiliation without an evolutionary physiological advantage. Similar to other behaviors of "Nose Touch" and passing the head/neck over or under the other's head/neck, the expression of the behavior by one horse and not the partner or more frequently by one horse suggests an individualized approach and preference to exhibiting affiliative interactions.

Differences in frequency within and between pairs indicate that each pair may have their own preference for behavioral expressions of affiliative interactions with proximity being the only common factor of indication of preferred partners. In most pairs, one horse would demonstrate a specific affiliative behavior (in some cases this occurred in much higher frequencies than for other behaviors or in other pairs) which could indicate a very specific preference for interactions and frequency for the interaction. Pairs demonstrated preference for behaviors in addition to proximity, usually exhibiting two other behaviors listed (only one included allogrooming) so that not all behaviors were present for all pairs. This suggests that horses have preferential affiliative behaviors they express with their partners that are unique for individuals as well as pairs.

Observations of increases in affiliative behaviors (focusing mostly on proximity and allogrooming) between pairs has been used to support improved management practices for housing horses and increase prevalence of group housing [35-37]. Furthermore, research shows that psychological welfare often improves when horses are housed in group environments [38-42] so a better understanding of affiliative behaviors can serve to support development in management practices.

\section{Conclusion}

Additional studies need to be conducted to examine behaviors of more pairs at this facility in addition to other pairs living in large stable social environments in which they can freely choose friends and partners from a large selection of horses in a large area with free mobility (to freely escape from those who demonstrate agonistic or aggressive behaviors as to demonstrate desire for more space versus close proximity to provide for clarity of proximity preference). Additional studies need to be done in smaller herds to look at how and when horses may choose to demonstrate affiliative behaviors and under what conditions they may choose to avoid partnering with others. Further research should also take into consideration how these behaviors may also carry over into interspecies relationships, especially those with humans in order to better inform equine welfare and management practices and equine-assisted programs.

Much like the types of behaviors humans use to convey affection for partners will often fall within certain categories; horses may also have these same tendencies where individuals may choose how, when, and with whom, to share their affection based on their own unique behavioral preferences or choice in "love language". A greater understanding of individualized expression of affiliation and friendship can inform welfare practices by observing if and how horses choose to express different affiliative behaviors. These same behaviors may also help to inform practices in human-horse interactions where individuals can have more defined criteria when determining equine emotional states when interacting with people.

\section{Acknowledgements}

The authors would like to thank the Noble Equine Center for supporting this study. 


\section{References}

1. Engelmann JM, Herrmann E (2016) Chimpanzees Trust Their Friends. Current Biology 26(2): 252-256.

2. Massen JJM, Koski SE (2014) Chimps of a feather sit together: Chimpanzee friendships are based on homophily in personality. Evolution and Human Behavior 35(1): 1-8.

3. Massen JJM, Sterck EHM, De Vos H (2010) Close social associations in animals and humans: Functions and mechanisms of friendship. Behaviour 147(11): 13791412.

4. Ramirez I Olle M (2019) Friendship as a scientific method. Sociological Review 67(2): 299-317.

5. Engelmann JM, Haux LM, Herrmann E (2019) Helping in young children and chimpanzees shows partiality towards friends. Evolution and Human Behavior 40(3): 292-300.

6. Silk J (2016) Animal Behaviour: Friendship Enhances Trust in Chimpanzees. Current Biology 26(2): R76-R78.

7. Goffe AS, Zinner D, Fischer J (2016) Sex and friendship in a multilevel society: behavioural patterns and associations between female and male Guinea baboons. Behavioral Ecology and Sociobiology 70(3): 323-336.

8. Moscovice LR, Di Fiore A, Crockford C, Kitchen DM, Wittig $\mathrm{R}$, et al. (2010) Hedging their bets? Male and female chacma baboons form friendships based on likelihood of paternity. Animal Behaviour 79(5): 1007-1015.

9. Snijders L, Naguib M (2017) Chapter EightCommunication in Animal Social Networks: A Missing Link?. Advances in the Study of Behavior 49: 297-359.

10. Christensen JW, Ladewig J, Sondergaard E, Malmkvist J (2002) Effects of individual versus group stabling on social behaviour in domestic stallions. Applied Animal Behaviour Science 75(3): 233-248.

11. Christensen JW, Sondergaard E, Thodberg K, Halekoh U (2011) Effects of repeated regrouping on horse behaviour and injuries. Applied Animal Behaviour Science 133(3-4): 199-206.

12. Curry MR, Eady PE, Mills DS (2007) Reflections on mare behavior: Social and sexual perspectives. Journal of Veterinary Behavior Clinical Applications and Research 2(5): 149-157.

13. Mills DS, Clarke A (2007) Housing, Management and Welfare. The Welfare of Horses, pp: 77-97.
14. Proops L, Burden F, Osthaus B (2012) Social relations in a mixed group of mules, ponies and donkeys reflect differences in equid type. Behavioural Processes 90(3): 337-342.

15. Mcgreevy P, Mclean A, Buckley P, Mcconaghy F, Mclean C (2011) How riding may affect welfare: What the equine veterinarian needs to know. Equine Veterinary Education 23(10): 531-539.

16. Waran N, Randle H (2017) What we can measure, we can manage: The importance of using robust welfare indicators in Equitation Science. Applied Animal Behaviour Science 190: 74-81.

17. Yarnell K, Hall C, Billett E (2013) An assessment of the aversive nature of an animal management procedure (clipping) using behavioral and physiological measures. Physiology \& Behavior 118: 32-39.

18. Nagy K, Bodo G, Bardos G, Banszky N, Kabai P (2010) Differences in temperament traits between crib-biting and control horses. Applied Animal Behaviour Science 122(1): 41-47.

19. Wickens C, Brooks SA (2020) Genetics of Equine Behavioral Traits. Veterinary Clinics of North America Equine Practice 36(2): 411-424.

20. Pierard M, McGreevy P, Geers R (2019) Effect of density and relative aggressiveness on agonistic and affiliative interactions in a newly formed group of horses. Journal of Veterinary Behavior 29: 61-69.

21. VanDierendonck MC, Spruijt BM (2012a) Coping in groups of domestic horses - Review from a social and neurobiological perspective. Applied Animal Behaviour Science 138(3-4): 194-202.

22. Feh C, de Mazieres J (1993) Grooming at a preferred site reduces heart rate in horses. Animal Behaviour 46(6): 1191-1194.

23. Kimura R (1998) Mutual grooming and preferred associate relationships in a band of free-ranging horses. Applied Animal Behaviour Science 59(4): 265-276.

24. Van Dierendonck MC, Sigurjonsdottir H, Colenbrander B, Thorhallsdottir AG (2004) Differences in social behaviour between late pregnant, post-partum and barren mares in a herd of Icelandic horses. Applied Animal Behaviour Science 89(3-4): 283-297.

25. Van Dierendonck MC, Goodwin D (2005) Social contact in horses: implications for human-horse interactions. In The human-animal relationship pp: 65-81. 
26. VanDierendonck MC, de Vries $H$, Schilder $M B H$, Colenbrander B, Thorhallsdottir AG, et al. (2009) Interventions in social behaviour in a herd of mares and geldings. Applied Animal Behaviour Science 116(1): 6773.

27. VanDierendonck MC, Spruijt BM (2012b) Coping in groups of domestic horses - Review from a social and neurobiological perspective. Applied Animal Behaviour Science 138(3-4): 194-202.

28. Maeda T, Ochi S, Ringhofer M, Sosa S, Sueur C, et al. (2021) Aerial drone observations identified a multilevel society in feral horses. Scientific Reports 11(1).

29. Bouskila A, Lourie E, Sommer S, De Vries H, Hermans ZM, et al. (2015) Similarity in sex and reproductive state, but not relatedness, influence the strength of association in the social network of feral horses in the Blauwe Kamer Nature Reserve. Israel Journal of Ecology and Evolution 61(2): 106-113.

30. Heitor F, do Mar Oom M, Vicente L (2006) Social relationships in a herd of Sorraia horses. Part II. Factors affecting affiliative relationships and sexual behaviours. Behavioural Processes 73(3): 231-239.

31. HeitorF,Oom Mdo M,Vicente L(2006) Social relationships in a herd of Sorraia horses. Part I. Correlates of social dominance and contexts of aggression. Behavioural Processes 73(2): 170-177.

32. Davis GH, Crofoot MC, Farine DR (2018) Estimating the robustness and uncertainty of animal social networks using different observational methods. Animal Behaviour 141: 29-44.

33. Draaisma R (2020) Language Signs and Calming Signals of Horses: Recognition and Application. CRC Press Taylor and Francis Group, Boca Raton, FL, USA, pp: 46-48.

34. Thorbergson ZW, Nielsen SG, Beaulieu RJ, Doyle RE (2016) Physiological and Behavioral Responses of
Horses to Wither Scratching and Patting the Neck When Under Saddle. Journal of Applied Animal Welfare Science 19(3): 245-259.

35. Boissy A, Manteuffel G, Jensen MB, Moe RO, Spruijt B, et al. (2007) Assessment of positive emotions in animals to improve their welfare. Physiology and Behavior 92(3): 375-397.

36. Janczarek I, Wiśniewska M, Wilk I, Liss M, Wnuk Pawlak E, et al. (2019) Assessment of affiliative behaviour in mares. Roczniki Naukowe Polskiego Towarzystwa Zootechnicznego 15(2).

37. Mellor DJ, Burns M (2020) Using the Five Domains Model to develop welfare assessment guidelines for Thoroughbred horses in New Zealand. New Zealand Veterinary Journal 68(3): 150-156.

38. Hartmann E, Søndergaard E, Keeling LJ (2012) Keeping horses in groups: A review. Applied Animal Behaviour Science 136(2-4): 77-87.

39. Rose Meierhöfer S, Klaer S, Ammon C, Brunsch R, Hoffmann G (2010) Activity behavior of horses housed in different open barn systems. Journal of Equine Veterinary Science 30(11): 624-634.

40. Topczewska J (2014) An attempt to assess the welfare of horses maintained in herd systems. Archives Animal Breeding 57(1).

41. Hall C, Goodwin D, Heleski C, Randle H, Waran N (2008) Is there evidence of learned helplessness in horses? Journal of Applied Animal Welfare Science JAAWS 11(3): 249-266.

42. Von Borstel UU, Duncan IJH, Shoveller AK, Merkies K, Keeling LJ, et al. (2009) Impact of riding in a coercively obtained Rollkur posture on welfare and fear of performance horses. Applied Animal Behaviour Science 116(2-4): 228-236. 